\title{
Nanofibrillated cellulose in wood coatings: mechanical properties of free composite films
}

\author{
Franziska Grüneberger • Tina Künniger • \\ Tanja Zimmermann • Martin Arnold
}

Received: 10 March 2014/Accepted: 28 May 2014/Published online: 18 June 2014

(c) Springer Science+Business Media New York 2014

\begin{abstract}
Composite films of nanofibrillated cellulose (NFC), derived from beech wood pulp, and 8 commercial acrylic and alkyd polymeric binders were prepared. Structural and mechanical properties of the composites were assessed by microscopy and tensile tests before and after aging. While the NFC was compatible with acrylate polymers, it formed undesired aggregates during processing with the alkyd polymers. Modulus of elasticity, tensile strength, and elongation at break of prepared films depended on the initial properties of the neat polymers. All composite films were stiffer, stronger, and less extensible than the corresponding neat polymer films. The reinforcing effect increased with increasing NFC content. Aging by artificial weathering strongly affected the mechanical properties of neat polymer and composite films. Alkyd films became, compared to the acrylate films, much stiffer and more brittle after artificial weathering. The results of the mechanical tests are regarded as promising step to use NFC as novel component in wood coatings.
\end{abstract}

F. Grüneberger $(\bowtie) \cdot$ T. Künniger · T. Zimmermann •

M. Arnold

Applied Wood Materials, Empa, Swiss Federal Laboratories for

Materials Science and Technology, Ueberlandstrasse 129,

8600 Dübendorf, Switzerland

e-mail: franziska.grueneberger@empa.ch

T. Künniger

e-mail: tina.kuenniger@empa.ch

T. Zimmermann

e-mail: tanja.zimmermann@empa.ch

M. Arnold

e-mail: martin.arnold@empa.ch

\section{Introduction}

Wood as complex, organic, and biodegradable compound is sensitive to UV radiation, water, mechanical impacts, and microorganisms [1]. All these factors damage an unprotected wood surface, decrease its durability, and change its appearance. Many polymeric binders with varying properties and specific advantages and disadvantages, such as acrylates, alkyds (oil-modified polyester resins), polyurethanes, epoxies, and others, are used for protective wood coatings [2]. Acrylates and alkyds are predominantly applied in outdoor applications. Here, suitable mechanical properties of coatings, such as strength, stiffness and ductility, are required to resist stresses due to swelling and shrinkage of the wood substrate. Additionally, functional additives are applied and many organic and inorganic compounds are introduced to coating systems to achieve improved UV, micro-organism or scratch resistance [3-6]. Agglomeration, migration, and leaching of these components are a known problem.

Related to these diverse requirements on protective coatings, nanofibrillated cellulose (NFC) could serve as a new multifunctional organic component for wood surface coatings to improve their efficiency. By adding NFC, mechanical properties could be enhanced and NFC could additionally act as a carrier for functional components such as UV absorbers or biocides.

NFC is a sustainable, biocompatible, and biodegradable polymer deriving from cellulose, the most abundant biopolymer on earth. NFC and other nanocellulose materials originate from different cellulose sources. Among others, they were already isolated from wood pulp, hemp, sugarbeet pulp, or even tunicates [7-10]. NFC was first isolated in 1983 by Turbak et al. [11] from wood pulp using a homogenizer. By now, different isolation procedures are 
established; among them, high-shear homogenization and grinding are the most favoured ones $[12,13]$. Isolated NFC fibrils have diameters between 5 and $100 \mathrm{~nm}$, lengths of more than $1 \mu \mathrm{m}$ and form network structures. NFC exhibits excellent mechanical properties at low weight, is translucent or transparent and is reactive due to the hydroxyl groups on the large fiber surface [14].

Many different composites were already produced by compounding NFC with a wide variety of polymers such as polyacrylates, polylactic acid, hydroxypropylcellulose, epoxy resins, natural rubber, or polyurethanes [15-20]. Mechanical properties of such composites change compared to the respective neat polymers [21]. The modulus of elasticity (MOE), which is a parameter describing the stiffness, increases after the addition of NFC, a stiff material with a high MOE. The tensile strength, which indicates the maximum stress a tested material can endure before failure, usually increases, as well. The elongation at break indicates how extensible or flexible a material is and the extensibility of polymers is usually reduced by adding NFC, which is less extensible than the neat polymers.

Many different applications of NFC and nanocellulose reinforced composites were already proposed and investigated, among others for biomedical and packaging applications and for electronic displays [22-24]. Using NFC for coating applications was also suggested; however, the main focus has been on paper and packaging coatings, intending improved mechanical, barrier and antimicrobial properties $[18,24,25]$. To our knowledge, only few reports on using NFC or other nanocelluloses in wood coating applications exist. Landry and Blanchet [26] used silane modified nanocrystalline cellulose to produce a hydrophobic wood coating. Jämsä et al. [27] used NFC to better distribute nanoparticles in wood coatings.
This work is part of a feasibility study, to investigate, if NFC is suitable for wood coating applications based on commercially used, water-borne polymeric binders. In an earlier publication, the fibrillation of the applied cellulose raw material and the characterisation of the resulting NFC were described. Moreover, the impact of NFC on the rheological properties of water-borne binders was evaluated [28].

Within the presented study, the impact of NFC on the mechanical properties of acrylic and alkyd polymer binders was examined, as well as the change of these properties due to aging.

\section{Materials and methods}

\section{Materials}

A refined fibrous beech wood pulp with 79 wt $\%$ cellulose content, $14 \mathrm{wt} \%$ hemicelluloses and $0.8 \mathrm{wt} \%$ residual lignin $\left(\right.$ Arbocel $^{\circledR}$, J. Rettenmeier \& Söhne GmbH \& Co. KG, Germany) was chosen as raw material for the production of NFC. 8 different, commercially available polymeric binders, 4 acrylate and 4 alkyd emulsions, were chosen to prepare polymer-NFC composites. Table 1 presents these polymer emulsions including their suppliers, their properties as declared by the suppliers and acronyms used in this paper. The additives used and their corresponding suppliers are included in Table 2.

\section{Preparation of NFC}

The used NFC was prepared as described before [28]. The beech wood pulp was diluted with deionized water to give a suspension of $1.5 \mathrm{wt} \%$ and swelled under stirring at

Table 1 Suppliers and types of used polymer emulsions

\begin{tabular}{|c|c|c|c|c|}
\hline Name & Commercial name & Supplier & Polymer and stabilization & $\begin{array}{l}\text { Solid } \\
\text { content }(\%)\end{array}$ \\
\hline Acr1 & Alberdingk AC 2739 & $\begin{array}{l}\text { Alberdingk Boley } \\
\text { GmbH, Germany }\end{array}$ & $\begin{array}{l}\text { Acrylic acid/methacrylic acid co-polymer emulsion, } \\
\text { surfactant free }\end{array}$ & $44-46$ \\
\hline Acr2 & Acronal DS 6288 & BASF SE, Germany & Anionic, acrylic emulsion & 44 \\
\hline Acr3 & Mowilith LDM 7416 & Celanese, USA & $\begin{array}{l}\text { Acrylic acid/methacrylic acid styrene co-polymer, } \\
\text { anionic surfactants }\end{array}$ & $49-51$ \\
\hline Acr4 & NeoCryl XK-98 & DSM N.V., Netherlands & Anionic, acrylic co-polymer emulsion & 44 \\
\hline Alk1 & Resydrol AY586 & Cytec Industries Inc., USA & $\begin{array}{l}\text { Surfactant free alkyd-acrylate emulsion (58\% fatty } \\
\text { acids) }\end{array}$ & 45 \\
\hline Alk2 & Uradil AZ-516 & DSM N.V., Netherlands & $\begin{array}{l}\text { Anionic, surfactant free alkyd emulsion ( } 63 \% \text { tall } \\
\text { oil) }\end{array}$ & $59-61$ \\
\hline Alk3 & W’Sol NW474 & Worlée, Germany & Alkyd emulsion (74 \% linseed oil) & 60 \\
\hline Alk4 & $\begin{array}{l}\text { W'Sol NW } 474 \\
(75 \mathrm{wt} \%)+\mathrm{E} \\
150 \mathrm{~W}(25 \mathrm{wt} \%)\end{array}$ & Worlée, Germany & Alkyd emulsion with linseed oils & 55 \\
\hline
\end{tabular}


Table 2 Standard formulations of polymer-NFC suspensions for preparation of polymer-NFC composite films with $2.5 \mathrm{wt} \%$ NFC content

\begin{tabular}{lllllllll}
\hline Component & \multicolumn{3}{l}{ Content in suspension (\%) } & & & \\
\cline { 2 - 8 } Polymeric binder acronym & Acr1 & Acr2 & Acr3 & Acr4 & Alk1 & Alk2 & Alk3 & Alk4 \\
\hline Solid content & 25 & 25 & 25 & 25 & 25 & 25 & 25 \\
NFC (dry/solid content) & 0.64 & 0.64 & 0.64 & 0.64 & 0.64 & 0.64 & 0.64 & 0.64 \\
Defoamer & $0.5^{\mathrm{a}}$ & $0.5^{\mathrm{a}}$ & $0.5^{\mathrm{b}}$ & $0.5^{\mathrm{b}}$ & $0.5^{\mathrm{b}}$ & $0.5^{\mathrm{b}}$ & $0.5^{\mathrm{c}}$ & $0.5^{\mathrm{c}}$ \\
Wetting agent & $0.2^{\mathrm{d}}$ & $0.2^{\mathrm{d}}$ & $0.2^{\mathrm{d}}$ & $0.2^{\mathrm{d}}$ & $0.2^{\mathrm{d}}$ & $0.2^{\mathrm{d}}$ & $0.2^{\mathrm{e}}$ & $0.2^{\mathrm{e}}$ \\
Film forming agent & - & - & - & 2.85 & - & - & - & - \\
Drying agent $^{\mathrm{g}}$ & - & - & - & - & 0.25 & 0.25 & 0.25 & 0.25 \\
Deionized water & 73.66 & 73.66 & 73.66 & 70.81 & 73.41 & 73.41 & 73.41 & 73.41 \\
Sum & 100 & 100 & 100 & 100 & 100 & 100 & 100 \\
\hline
\end{tabular}

${ }^{a}$ TEGO Foamex 822 (Evonik Tego Chemie GmbH, Germany)

b BYK-028 (BYK Additives \& Instruments, Germany)

c W'Add VP6410 (Worlée, Germany)

d BYK-348 (BYK Additives \& Instruments, Germany)

e W'Add 340 (Worlée, Germany)

${ }^{\mathrm{f}}$ butyl glycol (Alfa Aesar, USA)

g Octa Soligen Co 7 aqua (OMG Borchers GmbH, Germany)

$10{ }^{\circ} \mathrm{C}$ for 4 days. The swollen pulp was treated in an inline dispersing system (Megatron MT 3000, Kinematica AG, Switzerland) at $16000 \mathrm{rpm}$ for $25 \mathrm{~min} / \mathrm{kg}$ suspension. Afterward, the suspension was processed in a high pressure homogenizer (Microfluidizer ${ }^{\circledR}$, Microfluidics Corporation, USA) with two interaction chamber combinations and pressures up to 1200 bar. The suspension was first passed 10 times through chambers with diameters of 400 and $200 \mu \mathrm{m}(\mathrm{H} 230 \mathrm{z}, \mathrm{H} 30 \mathrm{z})$. Afterward, due to viscosity increase, the suspension was diluted to $1.3-1.4 \mathrm{wt} \%$ and was subsequently passed 10 times through chambers with diameters of 200 and $75 \mu \mathrm{m}(\mathrm{H} 30 \mathrm{z}, \mathrm{F} 20 \mathrm{y})$, respectively. The resulting NFC suspension was concentrated by centrifugation for storage at $5{ }^{\circ} \mathrm{C}$.

Films of neat cellulose raw material and neat NFC were prepared for tensile tests by solvent casting of a $0.5 \mathrm{wt} \%$ cellulose or NFC suspension, respectively, which was blended using a homogenizer (Ultra-Turrax T25 digital, IKA Werke, Germany) for $3 \mathrm{~min}$. After degassing, they were cast into a silicone mold and water evaporated at ambient conditions.

Preparation of polymer-NFC composite films

Polymer-NFC composite films were prepared using a standard coating formulation based on the suppliers' recommendations (Table 2).

For all compositions, a constant polymer solid content of $25 \mathrm{wt} \%$ was used. A defoamer, to minimize foaming during processing, a wetting agent for better substrate wetting, a film forming agent for Acr4, and a drying agent

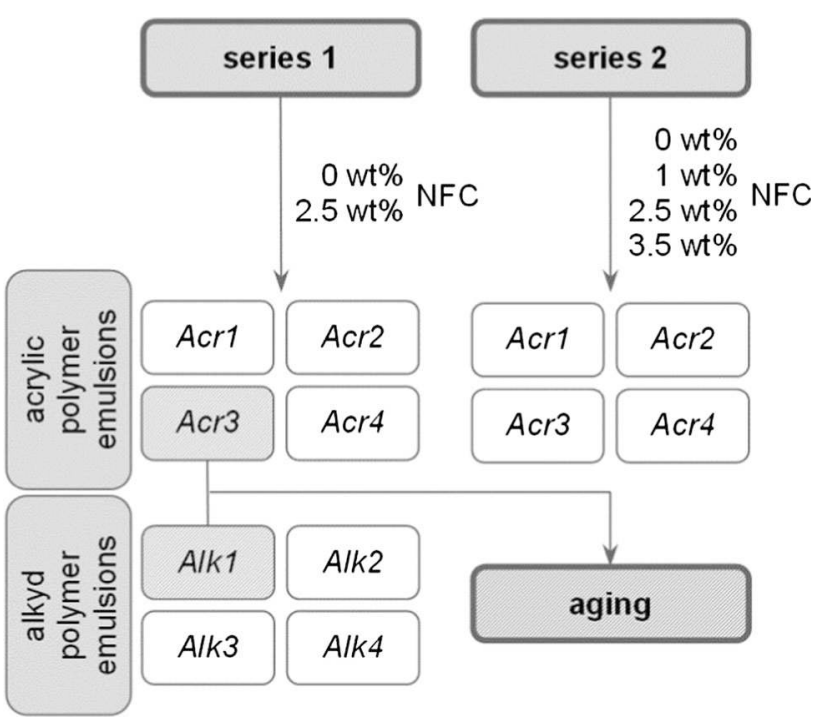

Fig. 1 Schematic overview of prepared test series

for the alkyds were used as essential additives for processing. NFC suspension was added to polymeric binders in different concentrations to generate two different sample series of polymer-NFC composites (Fig. 1). In the first series, all polymeric binders listed in Table 1 were used to test a broad variety of different binders. The composite polymer-NFC films contained $2.5 \mathrm{wt} \%$ of NFC relative to the solid polymer. Polymer-NFC composites of the second series were only prepared with the acrylic binders, but with different NFC contents. Concentrations were 1, 2.5 and $3.5 \mathrm{wt} \%$ of NFC relative to the solid polymer, which 
corresponds to $0.25,0.64$, and $0.91 \mathrm{wt} \% \mathrm{NFC}$ in the wet suspensions. This is a typical range of concentrations for coating additives. Higher NFC concentrations were impossible to process: the viscosity of these suspensions was too high and air bubbles were trapped in the suspensions, which were disadvantageous for film processing. Additionally, reference polymer films, further called neat polymer films, were prepared for both test series. Instead of aqueous NFC suspension, water was added to reach the same weight.

The polymer emulsions were diluted with the calculated amount of water. Afterward, additives were added while stirring with a dissolver stirrer. NFC suspension was added, and the whole suspension was stirred for $30 \mathrm{~min}$.

Polymer-NFC composite films were prepared using a bar coater with a $500 \mu \mathrm{m}$ gap onto a polypropylene (PP) foil. The PP foil was pre-treated with the wetting agent to enable a sufficient spreading of the polymer-NFC suspension. This was necessary, as the used polymer emulsions and formulations were developed for the much more hydrophilic substrate wood.

The bar coated films with an area of $\sim 60 \times 250 \mathrm{~mm}$ were dried at constant conditions of $20{ }^{\circ} \mathrm{C}$ and $65 \% \mathrm{RH}$ for at least 1 day, removed from the foil, and stored at the same climate.

Aging of polymer-NFC composite films

Polymer-NFC films without and with $2.5 \mathrm{wt} \%$ NFC were subjected to aging by artificial weathering (Fig. 1). One representative acrylate (Acr3) and alkyd (Alk1) were chosen, respectively. Free films were prepared as described above and were fixed onto birch plywood covered with white paper as supporting substrate. The prepared specimens were aged in a fluorescent UV accelerated weathering tester (QUV, Q-Lab, USA) according to ISO 11507. The films were exposed to UV light (UVA-340 lamps) with a peak irradiance set to $0.89 \mathrm{~W} / \mathrm{m}^{2}$ at $340 \mathrm{~nm}$ under constant temperature of $60{ }^{\circ} \mathrm{C}$ and dry humidity conditions for 24, 48, 96, 168, and $240 \mathrm{~h}$.

\section{Characterization}

\section{Scanning electron microscopy (SEM)}

SEM images were taken, to investigate the polymer-NFC interaction and to examine, if the NFC network structure was retained in the polymer matrix. Samples were prepared with two different methods. First, a drop of a polymerNFC suspension was placed onto a specimen holder, which had been laminated with a mica plate before. The drop was dried in vacuum and NFC-polymer interaction could be observed in cracks within the dried drop. Second, polymer-
NFC films with fractured surfaces from tensile tests were clamped into suitable sample holders. All samples were sputtered directly with a platinum layer of $8 \mathrm{~nm}$ (BALTEC MED 020 Modular High Vacuum Coating Systems, BAL-TEC AG, Lichtenstein). SEM images were recorded with a FEI Nova NanoSEM 230 instrument (FEI, USA) with an accelerating voltage of $5 \mathrm{kV}$ and a working distance of $5 \mathrm{~mm}$.

\section{Tensile tests}

Mechanical properties of the cellulose raw material, neat NFC, neat polymer, and composite films before and after aging were assessed via tensile tests on free films. Small bone shaped specimens were cut from the free films. The specimens had an overall length of $50 \mathrm{~mm}$ and widths of 4 and $9 \mathrm{~mm}$ in the stretching and clamping zone, respectively. Film thicknesses ranged between 60 and $160 \mu \mathrm{m}$. Specimens were oriented longitudinally and transversally relative to the direction of film preparation. The specimens were conditioned at $23{ }^{\circ} \mathrm{C}$ and $50 \% \mathrm{RH}$ for at least 2 days prior to testing. For the tensile tests, a universal testing machine (Zwick Z 010, Germany), equipped with a $200 \mathrm{~N}$ load cell and an optical strain detector were used. MOE, tensile strength $\left(\sigma_{\max }\right)$ and elongation at break $\left(\varepsilon_{\mathrm{B}}\right)$ were determined in accordance to EN ISO 527-1. Gauge length was $15 \mathrm{~mm}$, a pre-force of $0.1 \mathrm{~N}$ was applied to the specimens and the cross-head speed was set to $5 \mathrm{~mm} / \mathrm{min}$. MOE values were calculated from the initial slopes in the elastic region, mainly between 0.5 and $2 \mathrm{MPa}$ stress. At least five replicates were measured for each sample and average values were calculated.

\section{Results}

Tensile properties of neat NFC

Table 3 presents the mechanical properties of the cellulose raw material films and neat NFC films prepared by solvent casting. For comparison, reference data from literature summarized by Siró and Plackett [29] are also shown. NFC films exhibited about two times higher MOE, tensile strength and elongation at break than the initial cellulose raw material.

Preparation and appearance of polymer-NFC composite films

During the preparation of the polymer-NFC composite films differences between wet and dry acrylate and alkyd films containing NFC were observed. The wet acrylateNFC films exhibited a smooth, homogeneous surface and 
Table 3 Mechanical properties of NFC cellulose raw material films \pm standard deviation of at least five replicates

\begin{tabular}{llll}
\hline & $\operatorname{MOE}(\mathrm{GPa})$ & $\sigma_{\max }(\mathrm{MPa})$ & $\varepsilon_{\mathrm{B}}(\%)$ \\
\hline Cellulose raw material & $3.5 \pm 0.8$ & $45 \pm 7$ & $4.5 \pm 1.5$ \\
NFC & $6.3 \pm 1.5$ & $90 \pm 18$ & $8.4 \pm 2.5$ \\
NFC from literature $^{\mathrm{a}}$ & $2.5-17.5$ & $67-312$ & $2.1-11.5$ \\
\hline
\end{tabular}

a Values taken from Ref. [30]

the dry films showed smooth, slightly structured surfaces. In contrast, small particles, considered as NFC agglomerates, were visible in the wet alkyd-NFC suspension. In the dried film, no single particles were distinguishable, as they were integrated into the very rough film structure. All dry composite films were translucent, the acrylate films milky white and the alkyds milky yellow. The NFC-free polymer films were transparent and some of the alkyd films exhibited rough, fingerprint-like structures.

Figure 2 shows the SEM images of cracks in dried drops of Acr3-NFC (2a) and Alk3-NFC (2b) suspensions as representatives of each polymer class. In the Acr3-NFC suspension, polymer particles were located inside the NFC network, resting on the NFC fibrils (Fig. 2a). The image of the Alk3-NFC suspensions is far different. In Fig. $2 b$ a nearly pure NFC network is surrounded by the polymer. The NFC seems to repel the polymer and only few polymer particles were directly placed on the fiber surfaces.

Figure 3 shows fracture surfaces after tensile tests of neat polymer, Acr3-NFC and Alk3-NFC films before and after aging, respectively. Both neat polymer fracture surfaces (Fig. 3a, b) were comparatively smooth and without any further defects. Fibrils, probably ruptured during the tensile tests, stuck out of the Acr3-NFC film (Fig. 3c). Such structures were distributed over the whole fracture surface and only small parts of the surface were free of NFC. In contrast, no fibers were visible on the fracture surface after the tensile test of the Alk3-NFC composite film (Fig. 3d), but in comparison to the neat polymer film (Fig. 3b), the surface was much rougher. After aging, both polymer-NFC films showed smoother fracture surfaces than before aging (Fig. 3e, f).

\section{Tensile tests on polymer-NFC composites}

Test series 1: polymer-NFC composite films with acrylates and alkyds at $2.5 \mathrm{wt} \% \mathrm{NFC}$ concentration

Stress-strain diagrams of selected specimens of the first series of tensile tests with neat polymer films and polymerNFC composite films are displayed in Fig. 4 and summarized in Table 4 . The polymers showed very different stress-strain behavior even within the same polymer class. In general, the acrylates exhibited higher tensile strengths, except for Acr2, and also partially higher elongations at break compared to the alkyds. All alkyds and the two acrylates Acr1 and Acr3 failed at elongations up to $100 \%$ with only little plastic deformation. In contrast, Acr2 and Acr4 showed high elongations before failure, 444 and $266 \%$ respectively. Additionally, the stress-strain curve of Acr4 exhibited a very different behavior compared to the other samples. Due to sample necking, followed by further elongation of the necked specimen part, the stress rapidly decreased and subsequently increased again until fracture.

Figure 5 shows the effect of NFC addition on the MOE of composite films with $2.5 \mathrm{wt} \% \mathrm{NFC}$ in relation to the MOE of the corresponding neat polymer films. The MOE increased after addition of $2.5 \mathrm{wt} \% \mathrm{NFC}$ to the polymer independent of the type of polymer. The polymers became
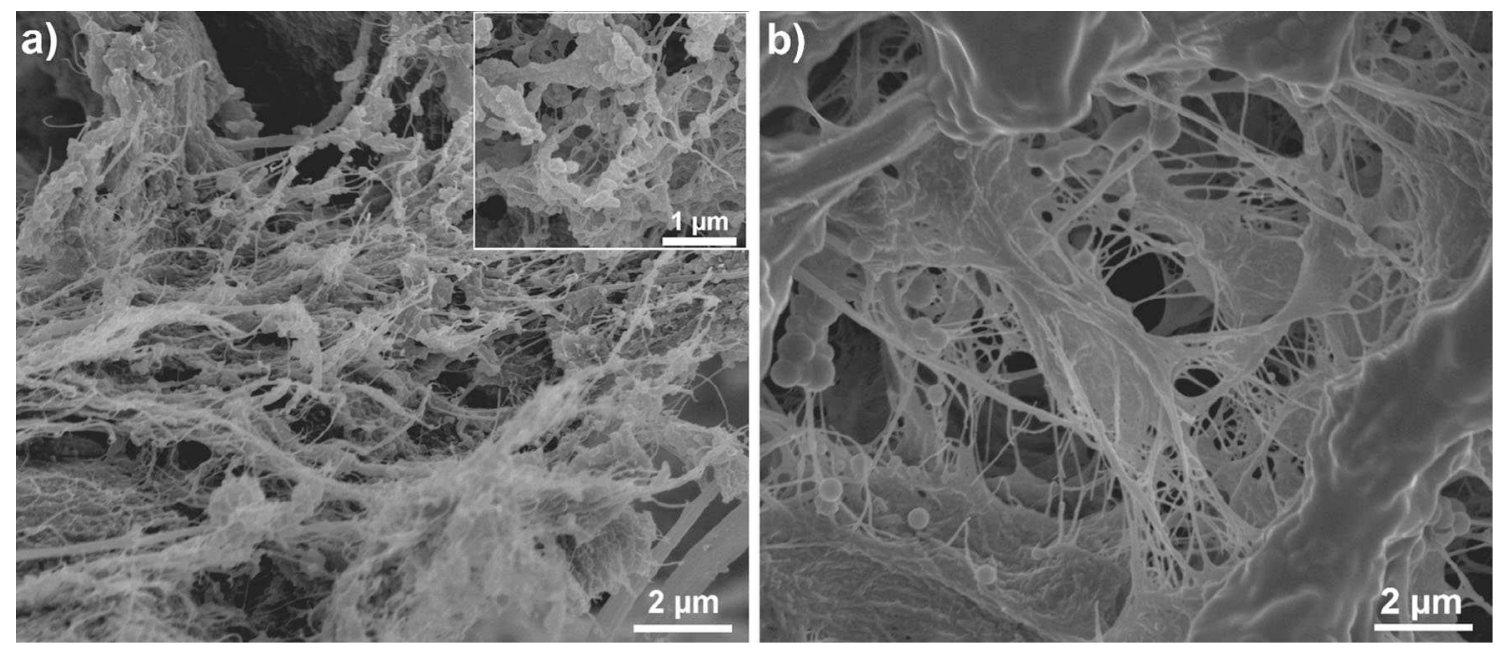

Fig. 2 SEM image of structures in open cracks in dried drops of Acr3-NFC suspension (a) and Alk3-NFC suspension (b), both at 2.5 wt\% NFC concentration relative to solid polymer 

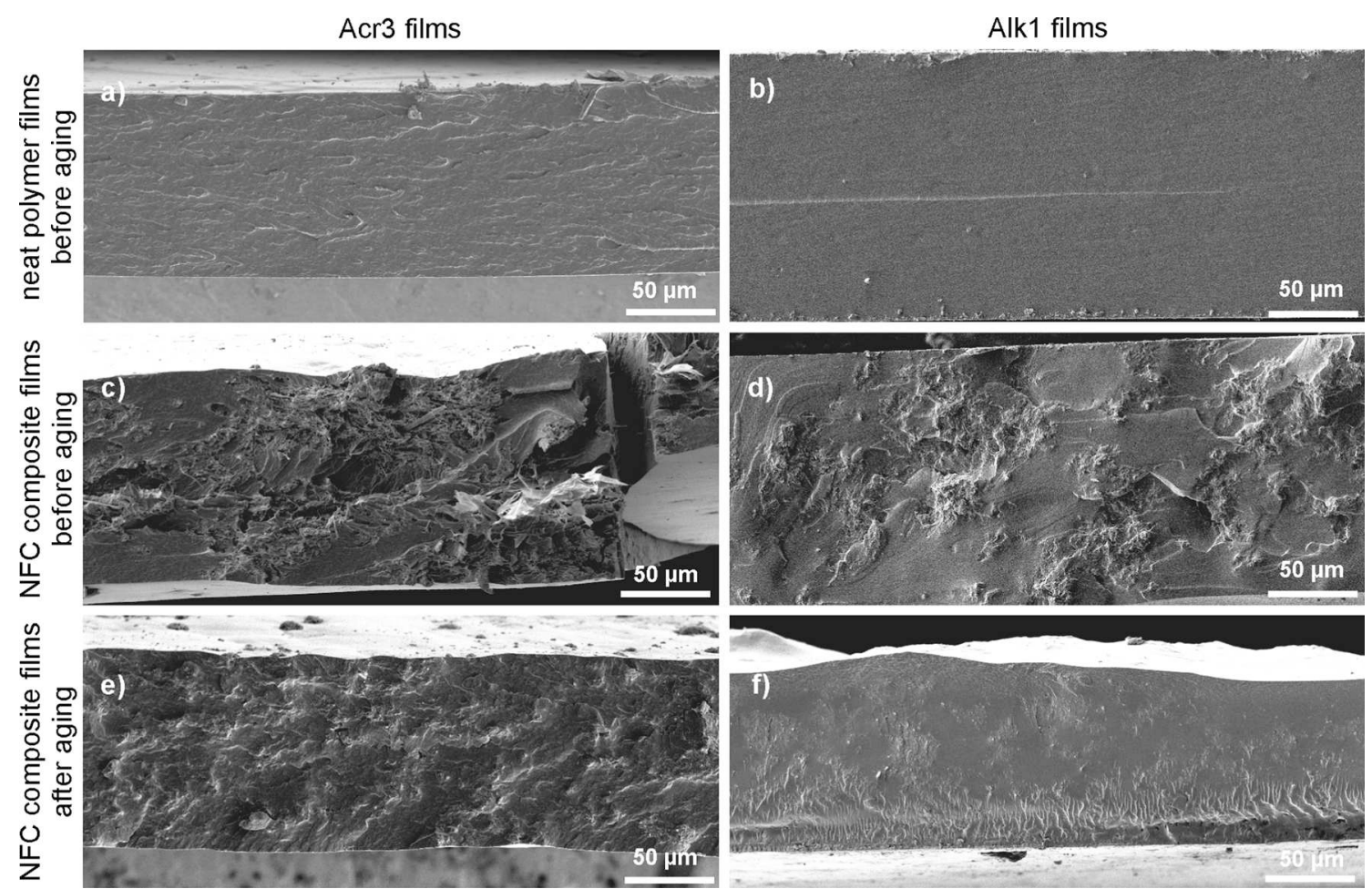

Fig. 3 SEM images of fracture surfaces of neat Acr3 and Alk1 films and corresponding composite films with 2.5 wt $\%$ NFC before and after aging

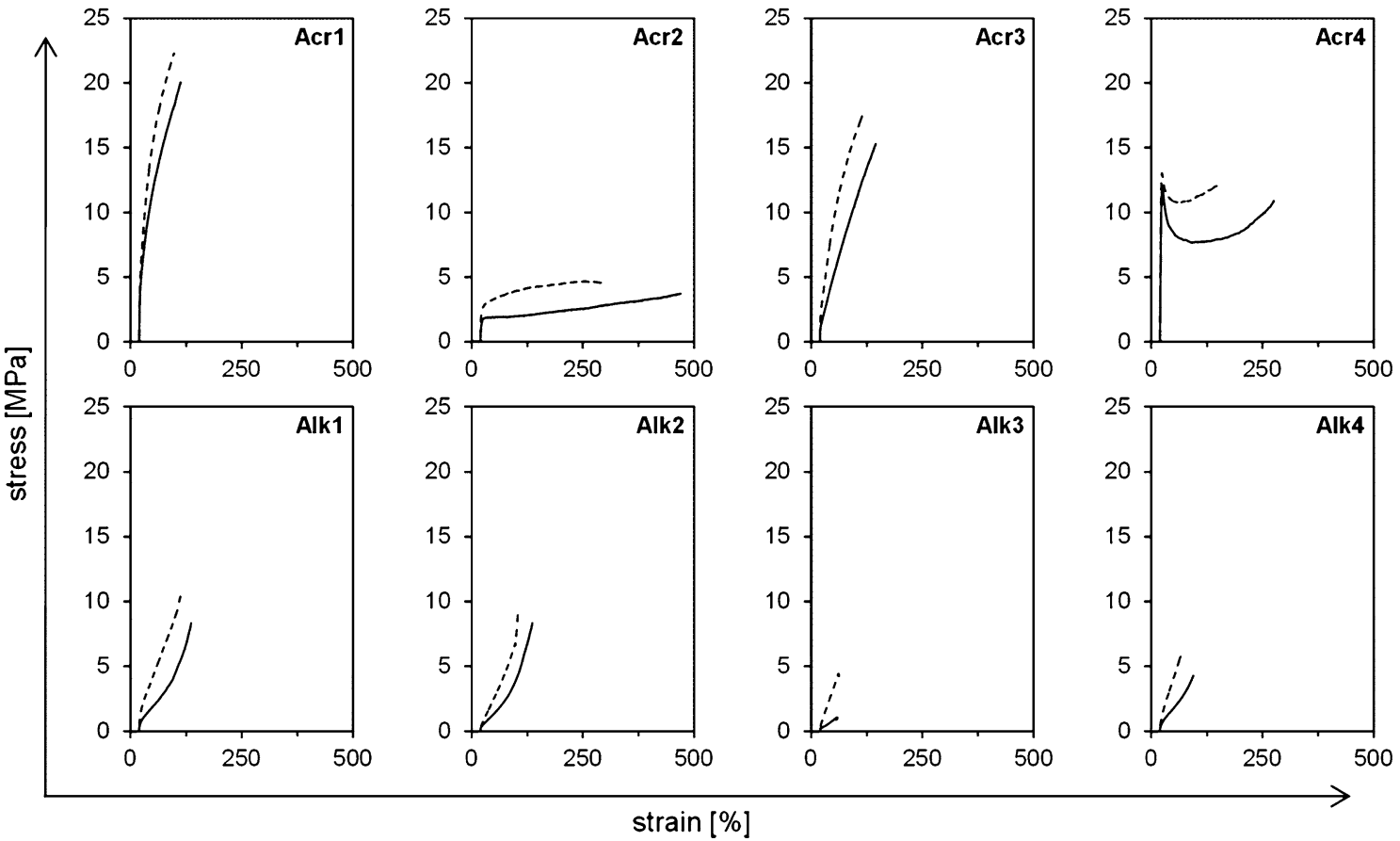

Fig. 4 Stress-strain diagrams of composite films with $2.5 \mathrm{wt} \%$ NFC (dashed line) and neat polymer films (straight line); curves are offset with $+20 \%$ strain to show initial slope

stiffer after the reinforcement and therefore all data points were above the 1:1 line, which represents the theoretical regression line without reinforcing effect. The MOE of composite films in Fig. 5 was shifted upwards by about $50 \mathrm{MPa}$, with some slight dependence on the initial MOE of the neat polymer. The calculated ratios of the MOEs of 
Table 4 Mechanical properties of test series 1 of neat polymer and polymer-NFC composite films before aging \pm standard deviation of at least five replicates and corresponding ratios

\begin{tabular}{|c|c|c|c|c|c|c|c|}
\hline Comp & te/polymer film & MOE & $\sigma_{\max }$ & $\varepsilon_{\mathrm{B}}(\%)$ & 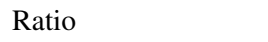 & Ratio & Ratio \\
\hline Acr1 & Neat polymer & $238 \pm 28$ & $19 \pm 2$ & $81 \pm 19$ & 1.20 & 1.16 & 0.95 \\
\hline & With $2.5 \mathrm{wt} \%$ NFC & $285 \pm 35$ & $22 \pm 1$ & $77 \pm 5$ & & & \\
\hline Acr2 & Neat polymer & $67 \pm 9$ & $3.7 \pm 0.1$ & $444 \pm 31$ & 1.99 & 1.22 & 0.64 \\
\hline & With 2.5 wt $\%$ NFC & $133 \pm 19$ & $4.5 \pm 0.3$ & $282 \pm 19$ & & & \\
\hline Acr3 & Neat polymer & $106 \pm 12$ & $15 \pm 2$ & $124 \pm 19$ & 2.21 & 1.20 & 0.80 \\
\hline & With 2.5 wt $\%$ NFC & $234 \pm 39$ & $18 \pm 1$ & $99 \pm 5$ & & & \\
\hline Acr4 & Neat polymer & $408 \pm 31$ & $10 \pm 1$ & $266 \pm 22$ & 1.14 & 1.30 & 0.511 \\
\hline & With $2.5 \mathrm{wt} \%$ NFC & $467 \pm 33$ & $13 \pm 0.5$ & $136 \pm 13$ & & & \\
\hline Alk1 & Neat polymer & $56 \pm 13$ & $7.9 \pm 1.0$ & $115 \pm 8$ & 1.75 & 1.14 & 0.71 \\
\hline & With 2.5 wt $\%$ NFC & $98 \pm 16$ & $9.0 \pm 0.3$ & $82 \pm 3$ & & & \\
\hline Alk2 & Neat polymer & $14 \pm 2$ & $5.8 \pm 0.8$ & $94 \pm 7$ & 2.14 & 1.22 & 0.84 \\
\hline & With 2.5 wt $\%$ NFC & $30 \pm 5$ & $7.1 \pm 0.3$ & $79 \pm 3$ & & & \\
\hline Alk3 & Neat polymer & $2.8 \pm 0.6$ & $1.1 \pm 0.2$ & $41 \pm 7$ & 8.21 & 4.00 & 1.07 \\
\hline & With $2.5 \mathrm{wt} \%$ NFC & $23 \pm 4$ & $4.4 \pm 0.2$ & $44 \pm 4$ & & & \\
\hline Alk4 & Neat polymer & $28 \pm 5$ & $4.4 \pm 0.5$ & $75 \pm 4$ & 2.25 & 1.34 & 0.64 \\
\hline & With 2.5 wt $\%$ NFC & $63 \pm 10$ & $5.9 \pm 0.3$ & $48 \pm 2$ & & & \\
\hline
\end{tabular}

composite films divided by the MOEs of the neat polymer films support these findings (compare Table 4). It should be mentioned that before aging, the tested alkyd films had a lower stiffness than the acrylic films with MOEs ranging from 14 to $56 \mathrm{MPa}$ for the neat alkyds compared to 67-408 MPa for the neat acrylics.

The reinforcing effect of the NFC was confirmed by the increased tensile strength and the decreased elongation at break as seen in Fig. 4.

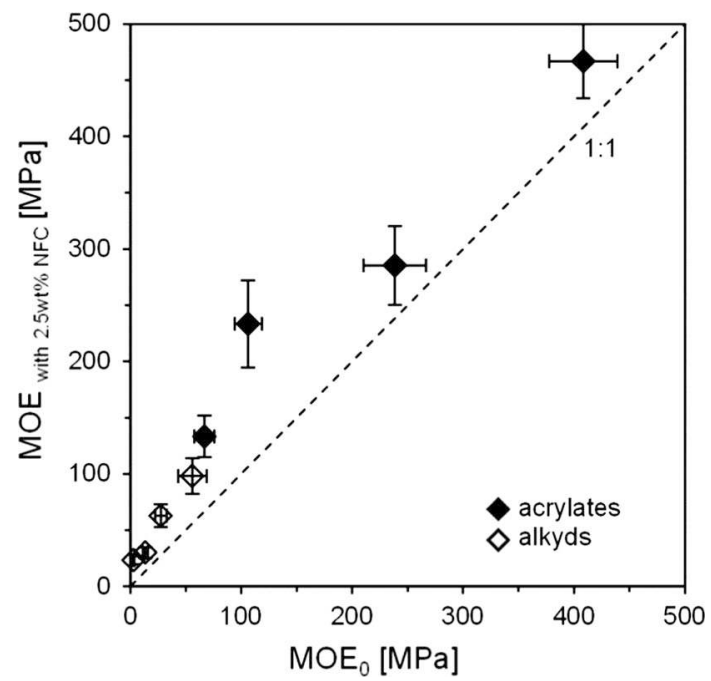

Fig. $5 \mathrm{MOE}$ of composite films with $2.5 \mathrm{wt} \% \mathrm{NFC}$ in relation to the $\mathrm{MOE}$ of the corresponding neat polymer film; the bars correspond to the standard deviation of at least five replicates and the reinforcing effect is shown in relation to the theoretical 1:1 line
The orientation of the tensile testing specimens relative to the direction of film preparation was also evaluated and found to have no impact on the tensile properties (data not shown).

Test series 2: acrylate-NFC composites with different NFC concentrations

The second test series comprised only the four acrylic polymers due to their better compatibility with NFC and acrylate-NFC composite films at different NFC concentrations $(1,2.5,3.5 \mathrm{wt} \%)$ were tested. Figure 6 shows exemplarily the effects of the NFC concentration on the stress-strain behavior of Acr3-NFC composite films. With increasing NFC concentration, the stiffness increased, higher stresses were needed to fracture the tested

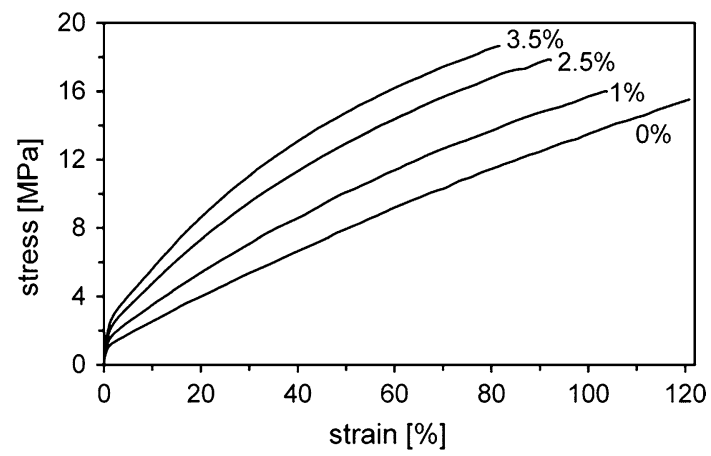

Fig. 6 Stress-strain diagram of Acr3-NFC composites with different NFC concentrations 
specimens and the extensibility decreased. The same behavior was observed for the three other tested acrylates.

Figure 7 summarizes the results of all tested specimens. The MOE (7a) and the elongation at break (7c) were more affected by NFC addition than the tensile strength (7b). The resulting mechanical properties of acrylate films due to NFC addition also depended on the properties of the individual acrylate. Their initial properties still dominated the mechanical properties of the acrylate-NFC composites. It was evident in Fig. $7 \mathrm{c}$ that the decrease of the elongation at break was more apparent for polymers with a high initial elongation at break (Acr2/Acr4) compared to the polymers with lower initial values (Acr1/Acr3). The according tendency of the MOE and the tensile strength is not clearly visible in Fig. 7a, b. For this reason, the ratios of the MOE of composite films and the corresponding MOE of the neat polymers were plotted against the MOE of the neat polymers (Fig. 8). Apparently, the reinforcing effect of the NFC increased with decreasing initial MOE of the neat polymer films. E.g., the initial MOE of the neat Acr2 polymer film was the lowest and therefore the MOE-ratios were the highest at all NFC concentrations. Moreover, the
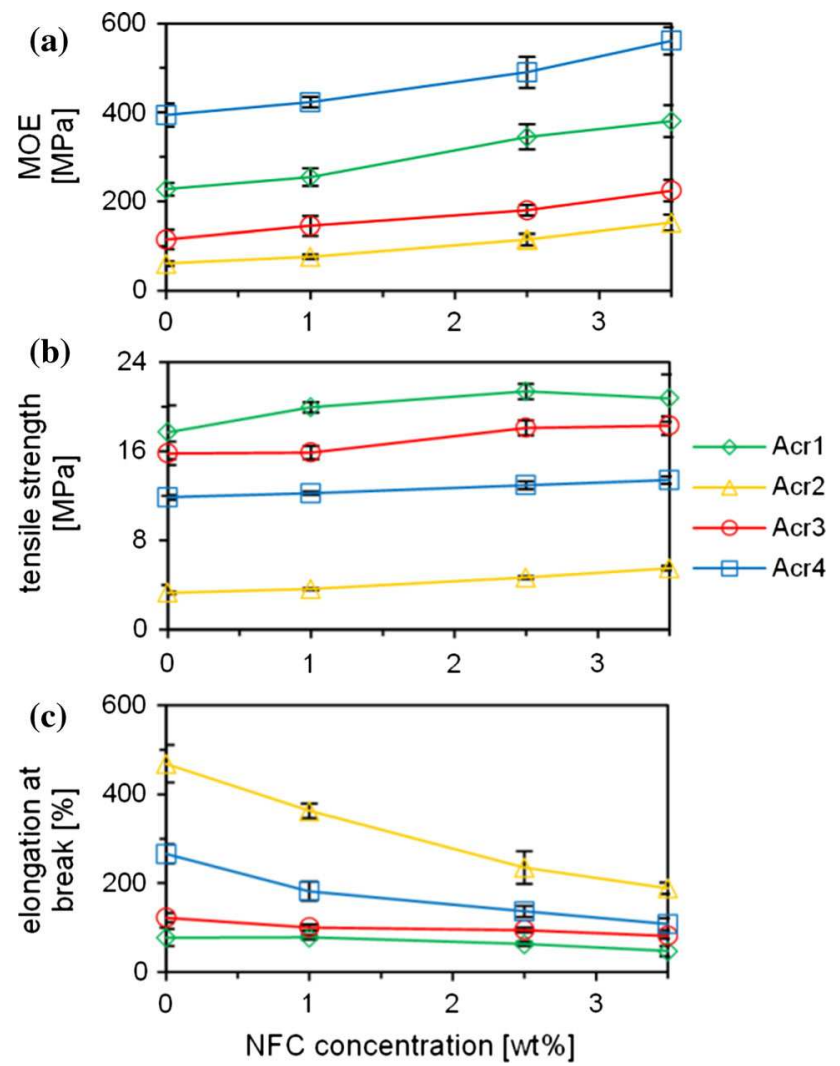

Fig. 7 MOE (a), tensile strength (b) and elongation at break (c) of acrylate-NFC composite films depending on NFC concentration; the error bars correspond to the standard deviation of at least five replicates

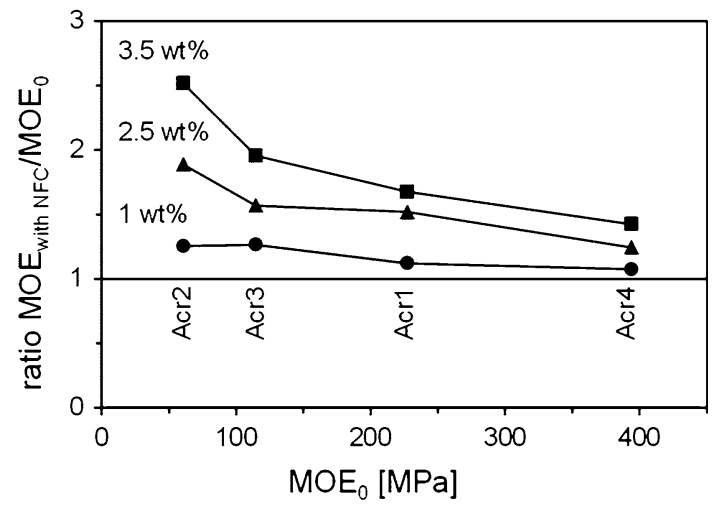

Fig. 8 Ratio of MOE of acrylate-NFC composite films with different NFC concentrations $\left(\mathrm{MOE}_{\mathrm{with}} \mathrm{NFC}\right)$ and $\mathrm{MOE}$ of neat polymer $\left(\mathrm{MOE}_{0}\right)$ depending on $\mathrm{MOE}_{0}$

influence of the initial polymer properties on the reinforcing effect of NFC was more pronounced at higher NFC concentration. A similar trend was found for the tensile strength: the ratios increased with decreasing initial tensile strength.

Aging of polymer-NFC composite films

The results of the aging experiments by artificial weathering for films with and without NFC are displayed in Figs. 9 and 10. The Acr3-NFC and Alk1-NFC films with $2.5 \mathrm{wt} \%$ NFC content changed their stress-strain behavior remarkably depending on the weathering time. The Acr3NFC films became stiffer (increased MOE) at constant elongation at break upon aging. Additionally, the tensile

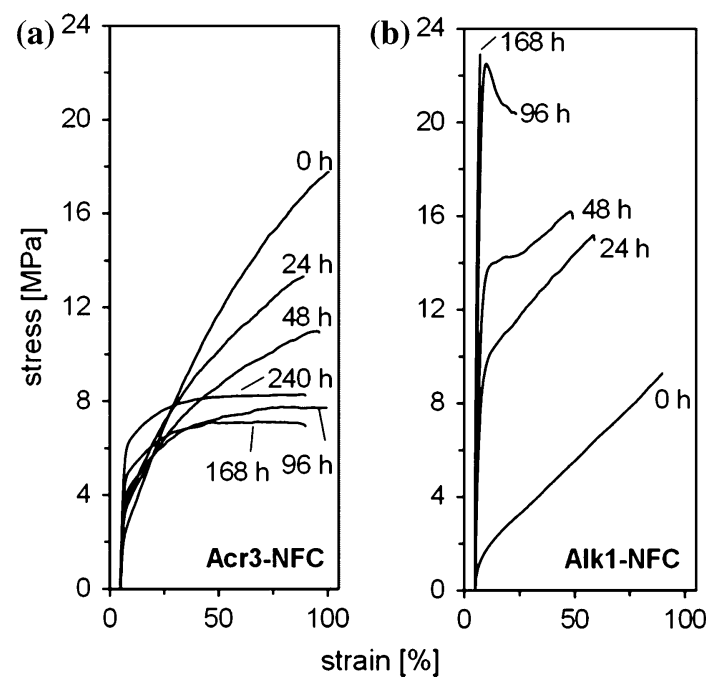

Fig. 9 Stress-strain diagrams of composite films with $2.5 \mathrm{wt} \%$ NFC of acrylate Acr3 (a) and alkyd Alk1 (b) after different aging times; curves are offset with $+5 \%$ strain to show initial slope 

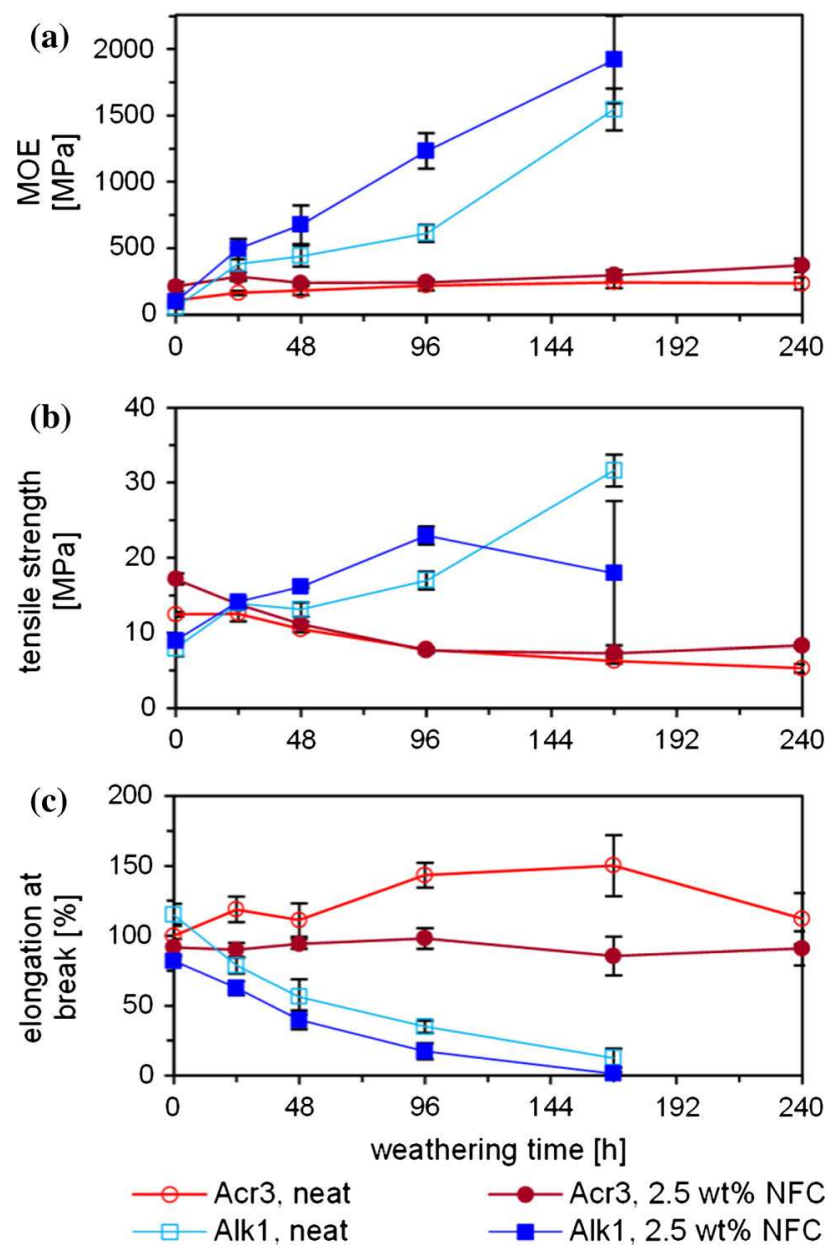

Fig. $10 \mathrm{MOE}$, tensile strength and elongation at break of Acr3 and Alk1 films during aging; the error bars correspond to the standard deviation of at least five replicates

strength decreased up to $96 \mathrm{~h}$ of aging and then levelled off. The Alk1-NFC films behaved differently, as MOE and tensile strength increased and elongation at break decreased during aging. Changes were much more pronounced for the alkyd films compared to the acrylic. After $168 \mathrm{~h}$ of aging, the MOE of the Alk1 films (Fig. 10a) increased distinctly, being up to 28 times higher than before aging. In comparison, the MOE of Acr3 films increased less, although their values roughly doubled. Alk1 films after $240 \mathrm{~h}$ of weathering became too brittle to prepare intact specimens for testing and therefore reliable results could not be achieved. For this reason, these data were not included in Figs. 9 and 10.

In contrast to the big differences between the two polymer types, the influence of NFC content during the aging was less distinct (Fig. 10). The general stress-strain behavior of neat and NFC containing films of the same polymer was the same, only the extent of change differed to comparably low extent.

\section{Discussion}

Protective coatings on wooden surfaces face challenging demands: on the one hand, they should protect the wood from exterior impacts such as water, light, and microorganisms and on the other hand, coatings have to endure high mechanical stresses during their service life. Mechanical stresses are not only caused by external impacts including scratching or hailstone impact, but also by dimensional changes of the wood substrate. Wood swells and shrinks due to changes in moisture, with a considerable variability depending mainly on the density and the anatomical direction. The largest dimensional changes occur in tangential direction, whereas the smallest changes are observed longitudinally. The maximum shrinkage and swelling of wood, which describes the difference in length between dry wood and swollen wood at fiber saturation, can be as high as $13.4 \%$ in tangential, $6.2 \%$ in radial and $0.6 \%$ in longitudinal direction for beech wood [30]. However, around local deformations or crack openings, considerably larger dimensional changes are possible. These dimensional movements have to be met by protective coatings with appropriate mechanical properties also at low temperatures and after exposure to the environment. For this reason, the mechanical effects of NFC addition to coating materials were investigated.

Eight commercial polymeric binder emulsions, classified into acrylic and alkyd type binders, were used for this study. According to the suppliers' information, they are suitable raw materials for exterior wood surface coatings. They were chosen to test the impact of NFC addition on the mechanical properties and the compatibility of NFC with a broad range of commercially used products.

\section{Compatibility between NFC and polymer emulsions}

Composites consisting of polymeric binders in combination with NFC were found to be macroscopically and microscopically different for acrylic or alkyd systems. For acrylic binders, a good compatibility between NFC and the polymer particles was indicated by the good dispersion of the NFC into the acrylic polymer emulsions and the homogeneous distribution of the polymer particles inside the fibrils network. We assume that the NFC network structure was retained within the composite films, which is supported by the SEM images of the fracture surface of the Acr3-NFC film (Fig. 3c). This is very important as evenly distributed NFC, which forms a percolating network in the polymer matrix, is known to be responsible for reinforcing effects in NFC composite materials [31].

In contrast, NFC seemed to be less compatible to the alkyd emulsions, as it was insufficiently dispersed in these emulsions. We assume repulsion between the NFC surface 
and the surface of the alkyd emulsion particles, which was supported by the SEM images of the representative Alk1NFC suspension (Fig. 2b).

The different behavior of acrylate and alkyd polymers with NFC in liquid and solid state could not be thoroughly explained. Within this study, commercial polymer emulsions were used, whose exact properties are not known in detail. For this reason and for a better understanding of polymer particle NFC interactions, further studies with model polymer emulsions are planned.

\section{Effects of NFC on mechanical properties of composites}

With regard to Fig. 4, the initial mechanical properties of the used polymeric binders showed considerable differences, although they are all sold commercially for the application in exterior wood coatings. Such differences between various polymers with regard to their mechanical properties as seen in Fig. 4 are well known from literature [32] and are attributed to the different chemical compositions of the different products.

All eight tested polymers were reinforced by the addition of NFC, while the polymer properties remained predominant for the behavior of the NFC-reinforced composites, as the general shape of the stress-strain curves did not change. The stiffness increased with increasing NFC concentration as well as the tensile strength, whereas the elongation at break decreased at the same time. Thus, the polymers were less extensible, but at the same time they could resist higher stresses after NFC addition. This reinforcing effect is well known and widely reported for fiber reinforced polymers in general and NFC composites in particular [21, 33].

With regard to the investigated polymers, it seems to be possible to estimate the MOE of NFC-reinforced polymer films and therefore the reinforcing effect of NFC addition, when the initial MOE of the neat polymer is known. We draw this conclusion from the close relation between the MOEs of the composites at all NFC concentrations and the initial MOEs of the neat polymers (compare data for $2.5 \mathrm{wt} \%$ NFC in Fig. 5). Looking at different NFC concentrations, we concluded from the steady increase or decrease of the three mechanical parameters as depicted in Fig. 7 that it is possible to control the mechanical properties of NFC composites with the tested polymers.

The results of test series 2 and the impact of NFC and polymer type were also compared with literature data for a better understanding and assessment of the reinforcing effect of the NFC in this work. Data from Malainine et al. [21] and Trovatti et al. [34] were chosen, because both research groups described composite preparation using acrylic emulsions and NFC or bacterial cellulose (BC), respectively. The data of composites with $1 \mathrm{wt} \%$ NFC content of Malainine et al. were in accordance with the results of our work. The MOE increased from 0.55 to $0.99 \mathrm{MPa}$ and the MOE-ratio of 1.8 confirmed that the films with initially low MOE exhibit higher reinforcement after NFC addition [21].

Comparing the data of Trovatti et al. [34], the reinforcing effect of our NFC on the chosen acrylic composites was different from the effect of $\mathrm{BC}$ on the two different acrylic emulsions (named SF and AC) of Trovattis work. Although the initial MOE of the neat acrylic polymer (SF) was very low, the corresponding MOE and MOE ratio of the composite films with 1 and $2.5 \mathrm{wt} \%$ NFC were comparably lower than those described in our paper. The MOE ratio of the $2.5 \mathrm{wt} \%$ film was only about 1.5 at an initial polymer MOE of approximately $9 \mathrm{MPa}$ (taken from Fig. 4 in Ref. [34]) compared to the MOE ratio of 1.9 of our Acr2, which had a higher initial MOE of the neat polymer $(61 \mathrm{MPa})$. Here, the origin of the nanocellulosic material, NFC versus BC, and the way of preparation, bar coating versus solvent casting and hot pressing, could be an explanation for these findings. Dufresne [35] already summarized that the reinforcing effect of NFC and the other nanocellulose materials depends on various parameters, which are the morphology and the sources of nanocelluloses, the processing method and the mechanical testing conditions.

\section{Effect of aging on mechanical properties of composites}

From practical experiences with acrylate and alkyd paints on wood surfaces it is known that cracks usually occur much earlier in alkyd coatings during weathering exposure [1]. This means that alkyds are expected to be stiffer and less extensible than the acrylates. This was not the case in our study before aging: the acrylates were stiffer, had mainly higher tensile strength than the alkyds and had comparable elongations at break. As considerable changes of mechanical properties of polymers after aging are widely reported in literature [36], films of Acr3 and Alk1 were subjected to aging by artificial weathering. Both chosen polymers were representatives of their polymer class and exhibited comparable fracture behavior before aging (compare Fig. 4). After aging at high temperature under UV radiation, the mechanical properties of Acr3 and Alk1 changed differently (Figs. 9, 10). Independently from the fact, if films contained NFC or not, the MOE and tensile strength of the Alk1 films after aging were far higher than those of the Acr3 films. The alkyd also became much less extensible that the acrylate.

It is emphasised that the addition of NFC to the Alk1 changed the mechanical properties less than aging, especially for the alkyd films. The initial MOE of the neat Alk1 film was increased less than twice after $2.5 \mathrm{wt} \% \mathrm{NFC}$ 
addition, but nearly seven times after only $24 \mathrm{~h}$ of aging and even 28 times after $168 \mathrm{~h}$.

From literature it is known that polymers embrittle mainly due to UV radiation which frequently causes increased MOE and tensile strength accompanied by decreased elongation at break [37, 38]. The intensive changes exhibited by the Alk1 films were mainly explained by the film formation process. Polymer coatings deriving from alkyd emulsions dry due to water evaporation and particle coalescence followed by chemical crosslinking and curing with the help of drying agents and catalysts, respectively [39]. In our case, the films dried at moderate temperatures and were also stored at constant climate before testing. During aging, the films were exposed to higher temperatures and also to UV radiation. Both impacts may have accelerated and re-initiated the curing and crosslinking process, leading to much higher crosslinking densities. Alkyd polymer films with increased amount of crosslinks lead to higher stiffness and also to higher tensile strength due to lower polymer network mobility.

Aging had less pronounced effects on the mechanical properties of the Acr3 films. Physical aging accompanied by continued film formation is a possible explanation for the observed results. Physical aging, also called annealing, describes the process of gaining thermodynamic equilibrium in the polymer network and was already described to increase the polymer stiffness $[38,40]$.

Additionally, polymer degradation by oxidative chemical reactions should be considered for both polymers [36]. It can be induced upon long term UV radiation, when network defects are introduced to the polymer. In how far such degradation and curing processes are superimposed in our comparably short aging experiment was not investigated. It should also be considered that our coating formulation did not contain light stabilizers, which would prevent or retard chemical degradation and which are usually included in commercial transparent coating formulations. We intentionally left them out of our very basic test formulation to minimize the amount of included substances, but they will be included in future experiments.

The tensile tests before and after aging showed that the results of tensile tests of polymer films have to be interpreted carefully with regard to the intended application as wood surface coating. The decrease of the elongation at break after NFC addition seems to be unfavorable. But with regard to the dimensional changes of wood, which are macroscopically in the range of 1-15\% [30] and therefore far lower than the elongation of the NFC polymer composites, this decrease of elongation is negligible. Nevertheless, highest stresses on coatings will occur at cracks in the wood surface. In how far a coating will endure these stresses cannot be estimated from tensile tests alone, since the performance also depends on the coating adhesion at the wooden surface [41].

\section{Conclusion}

Composite films from different acrylic and alkyd polymer emulsions and NFC, derived from beech wood pulp, were produced. The NFC was compatible to acrylate polymers, but formed undesired aggregates during processing with the alkyd polymers. We link this differing behavior to varying surface properties of the used polymer emulsions and therefore varying NFC polymer particle interaction, which was not further investigated. The dry polymer films exhibited very different stress-strain behavior, but all polymers were reinforced after the addition of NFC: they became stiffer (increased MOE), stronger (increased tensile strength) but therefore less extensible (decreased elongation at break). The reinforcing effect was increased with increasing NFC concentration and strongly depended on the initial properties of the polymers in so far that polymers with initially low MOEs were reinforced to a higher extent than polymers which already had a high initial MOE.

Acrylate and alkyd polymers before aging differed from each other, independent from the NFC content: alkyds were less stiff, had mainly lower tensile strengths and were comparably or less extensible than the acrylics. After aging, the alkyd films became much stiffer and much more brittle than the acrylate films, which is in accordance to practical experiences of these polymers in wood coating applications. Especially for the alkyds, the impact of aging on the mechanical properties was much higher than the effect of NFC addition. The presence of NFC in the films did not adversely influence the aging behavior.

Overall, NFC appears to be applicable in wood coatings, whereas the reinforcing effect seems to be of secondary importance for the coating performance. The prospective use of NFC functionalized with wood protecting components is currently in progress.

Acknowledgements This work was financially supported by the Swiss National Science Foundation (SNF) within the National Research Programme 66 (NRP66) "Resource Wood" Project-Nr 406640-136558). We kindly thank Anja Huch for performing SEM characterization. We are grateful for valuable comments and discussions on the manuscript with Ingo Burgert. We also thank the companies mentioned in the experimental part for providing the coating and cellulose raw materials.

\section{References}

1. Wicks ZW, Jones FN, Pappas SP, Wicks DA (2006) Exterior durability. Organic coatings. Wiley, Hoboken, pp 97-120 
2. Bulian F, Graystone JA (2009) Wood coatings-theory and practice, 1st edn. Elsevier Science, Amsterdam

3. Sow C, Riedl B, Blanchet P (2011) UV-waterborne polyurethane-acrylate nanocomposite coatings containing alumina and silica nanoparticles for wood: mechanical, optical, and thermal properties assessment. J Coat Technol Res 8(2):211-221

4. Blanchard V, Blanchet $P$ (2011) Color stability for wood products during use: effects of inorganic nanoparticles. Bioresources 6(2):1219-1229

5. Schaller C, Rogez D, Braig A (2012) Organic vs inorganic light stabilizers for waterborne clear coats: a fair comparison. J Coat Technol Res 9(4):433-441

6. Ren G, Hu D, Cheng EWC, Vargas-Reus MA, Reip P, Allaker RP (2009) Characterisation of copper oxide nanoparticles for antimicrobial applications. Int J Antimicrob Agent 33(6):587-590

7. Zimmermann T, Bordeanu N, Strub E (2010) Properties of nanofibrillated cellulose from different raw materials and its reinforcement potential. Carbohydr Polym 79(4):1086-1093

8. Helbert W, Cavaille JY, Dufresne A (1996) Thermoplastic nanocomposites filled with wheat straw cellulose whiskers. Part 1: processing and mechanical behavior. Polym Compos 17(4): 604-611

9. Agoda-Tandjawa G, Durand S, Berot S, Blassel C, Gaillard C, Garnier C, Doublier JL (2010) Rheological characterization of microfibrillated cellulose suspensions after freezing. Carbohydr Polym 80(3):677-686

10. Favier V, Chanzy H, Cavaillé JY (1995) Polymer nanocomposites reinforced by cellulose whiskers. Macromolecules 28(18):63656367

11. Turbak AF, Snyder FW, Sandberg KR (1983) Microfibrillated cellulose, a new cellulose product: properties, uses, and commercial potential. J Appl Polym Sci Polym Symp 37:815-827

12. Zimmermann T, Pöhler E, Geiger T (2004) Cellulose fibrils for polymer reinforcement. Adv Eng Mater 6(9):754-761

13. Iwamoto S, Nakagaito AN, Yano H, Nogi M (2005) Optically transparent composites reinforced with plant fiber-based nanofibers. Appl Phys A Mater 81(6):1109-1112

14. Klemm D, Kramer F, Moritz S, Lindström T, Ankerfors M, Gray D, Dorris A (2011) Nanocelluloses: a new family of nature-based materials. Angew Chem Int Ed 50(24):5438-5466

15. Favier V, Canova GR, Cavaille JY, Chanzy H, Dufresne A, Gauthier C (1995) Nanocomposite materials from latex and cellulose whiskers. Polym Adv Technol 6(5):351-355

16. Tingaut $P$, Zimmermann T, Lopez-Suevos F (2010) Synthesis and characterization of bionanocomposites with tunable properties from poly(lactic acid) and acetylated microfibrillated cellulose. Biomacromolecules 11(2):454-464

17. Lopez-Suevos F, Eyholzer C, Bordeanu N, Richter K (2010) DMA analysis and wood bonding of PVAc latex reinforced with cellulose nanofibrils. Cellulose 17(2):387-398

18. Ruiz MM, Cavaillé JY, Dufresne A, Graillat C, Gérard J-F (2001) New waterborne epoxy coatings based on cellulose nanofillers. Macromol Symp 169(1):211-222

19. Siqueira G, Tapin-Lingua S, Bras J, da Silva Perez D, Dufresne A (2011) Mechanical properties of natural rubber nanocomposites reinforced with cellulosic nanoparticles obtained from combined mechanical shearing, and enzymatic and acid hydrolysis of sisal fibers. Cellulose 18(1):57-65

20. Seydibeyoglu MO, Oksman K (2008) Novel nanocomposites based on polyurethane and micro fibrillated cellulose. Compos Sci Technol 68(3-4):908-914

21. Malainine ME, Mahrouz M, Dufresne A (2005) Thermoplastic nanocomposites based on cellulose microfibrils from Opuntia ficus-indica parenchyma cell. Compos Sci Technol 65(10): $1520-1526$
22. Yano H, Sugiyama J, Nakagaito AN, Nogi M, Matsuura T, Hikita M, Handa K (2005) Optically transparent composites reinforced with networks of bacterial nanofibers. Adv Mater 17(2):153-155

23. Eyholzer C, Borges de Couraça A, Duc F, Bourban PE, Tingaut P, Zimmermann T, Månson JAE, Oksman K (2011) Biocomposite hydrogels with carboxymethylated, nanofibrillated cellulose powder for replacement of the nucleus pulposus. Biomacromolecules 12(5):1419-1427

24. Aulin C, Ström G (2013) Multilayered alkyd resin/nanocellulose coatings for use in renewable packaging solutions with a high level of moisture resistance. Ind Eng Chem Res 52(7):2582-2589

25. Martins N, Freire C, Pinto R, Fernandes S, Pascoal Neto C, Silvestre A, Causio J, Baldi G, Sadocco P, Trindade T (2012) Electrostatic assembly of $\mathrm{Ag}$ nanoparticles onto nanofibrillated cellulose for antibacterial paper products. Cellulose 19(4):14251436

26. Landry V, Blanchet $P$ (2009) Coatings containing nanocrystalline cellulose, processes for preparation and use thereof. WO2011075 $837 \mathrm{~A} 1$

27. Jämsä S, Kataja K, Takala S, Putkisto K, Vastamäki P, Dyhr H (2010) Method for manufacturing paint or varnish. WO201112 4759 A1

28. Grüneberger F, Künniger T, Zimmermann T, Arnold M (2014) Rheology of nanofibrillated cellulose/acrylate systems for coating applications. Cellulose. doi:10.1007/s10570-014-0248-9

29. Siro I, Plackett D (2010) Microfibrillated cellulose and new nanocomposite materials: a review. Cellulose 17(3):459-494

30. Lohmann U (2003) Holz Lexikon. Holz Lexikon, 4th edn. DRWVerlag Weinbrenner GmbH \& Co, Leinfelden-Echterdingen

31. Favier V, Dendievel R, Canova G, Cavaille JY, Gilormini P (1997) Simulation and modeling of three-dimensional percolating structures: case of a latex matrix reinforced by a network of cellulose fibers. Acta Mater 45(4):1557-1565

32. Koleske JV (ed) (2012) Paint and coating testing manual, 15th edn. ASTM International, West Conshohocken. doi:10.1520/ MNL17-2ND-EB

33. Samir MASA, Alloin F, Dufresne A (2005) Review of recent research into cellulosic whiskers, their properties and their application in nanocomposite field. Biomacromolecules 6(2):612626

34. Trovatti E, Oliveira L, Freire CSR, Silvestre AJD, Pascoal Neto C, Cruz Pinto JJC, Gandini A (2010) Novel bacterial celluloseacrylic resin nanocomposites. Compos Sci Technol 70(7):11481153

35. Dufresne A (2012) Nanocellulose, from nature to high performance tailored materials. Walter de Gruyter, Berlin

36. Wypych G (2008) Handbook of material weathering, 4th edn. ChemTec Publishing, Toronto

37. Nichols M (2002) Anticipating paint cracking: the application of fracture mechanics to the study of paint weathering. J Coat Technol 74(924):39-46

38. Skaja A, Croll S, Fernando D (2006) Mechanical property changes and degradation during accelerated weathering of polyester-urethane coatings. JCT Res 3(1):41-51

39. Hofland A (1997) Making paint from alkyd emulsions. In: Glass JE (ed) Technology for waterborne coatings, ACS symposium series, vol 663. American Chemical Society, Washington, pp 183-195

40. Cangialosi D, Boucher VM, Alegria A, Colmenero J (2013) Physical aging in polymers and polymer nanocomposites: recent results and open questions. Soft Matter 9(36):8619-8630

41. Mader A, Schirò A, Brischetto M, Pizzo B (2011) Interactions and penetration of polymers and nanolatexes into wood: an overview. Prog Org Coat 71(2):123-135 